\title{
Commentary: Singling out single ventricles after Fontan
}

\author{
Karan R. Kumar, MD, and Christoph P. Hornik, MD, MPH
}

From the Department of Pediatrics and Duke Clinical Research Institute, Duke University School of Medicine, Durham, NC.

Dr Kumar receives support for research from the National Institutes of Health (grant No. T32GM086330). Dr Hornik receives salary support for research from the Eunice Kennedy Shriver National Institute of Child Health and Human Development (grant No. 1K23HD090239) and the US government and industry for his work in pediatric and neonatal clinical pharmacology (government contract No. HHSN267200700051C).

Received for publication Nov 7, 2018; accepted for publication Nov 8, 2018; available ahead of print Dec 12, 2018.

Address for reprints: Christoph P. Hornik, MD, MPH, Duke Clinical Research Institute, PO Box 17969, Durham, NC 27715 (E-mail: christoph.hornik@duke.edu).

J Thorac Cardiovasc Surg 2019;157:2016-7

$0022-5223 / \$ 36.00$

Copyright (c) 2018 by The American Association for Thoracic Surgery

https://doi.org/10.1016/j.jtcvs.2018.11.018

The Fontan palliation for patients with single-ventricle physiology has undergone considerable modification since its introduction in $1971 .{ }^{1}$ Over the past 2 decades, the atriopulmonary anastomosis has given way to the total cavopulmonary connection with an intracardiac lateral tunnel or an extracardiac conduit (Figure 1). Despite improvement in outcomes, the Fontan circulation remains compromised and long-term effects of this physiology, including venous congestion and decreased cardiac output, carry lifelong morbidity and mortality risks. ${ }^{2-4}$

Single-ventricle morphology and preoperative hemodynamic parameters have historically been the main predictors of deleterious late outcomes., ${ }^{5,6}$ More recently, prolonged postoperative intensive care unit (ICU) length

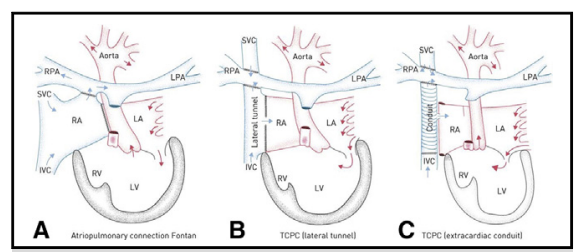

The Fontan circulation.

\section{Central Message}

Novel therapeutics and interventions are needed to address the late morbidity and mortality risks associated with unfavorable Fontan circulation characteristics.

See Article page 2005.

of stay (LOS) has been implicated in poorer prognosis. Complete characterization of the natural history of the Fontan circulation is essential in elucidating modifiable risk factors and developing beneficial interventions. Ono and colleagues ${ }^{8}$ report results of a single-center retrospective study of 483 patients over a 22 -year period aimed at identifying morphologic, hemodynamic, and perioperative risk factors for extended ICU LOS after Fontan palliation and describe their effect on longer-term outcomes. Their first key finding is that anomalous systemic venous drainage; aortopulmonary collaterals; elevated preoperative

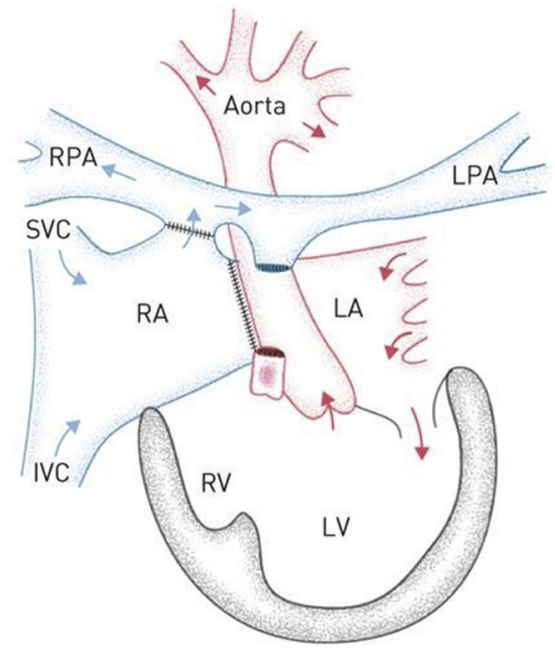

A

Atriopulmonary connection Fontan

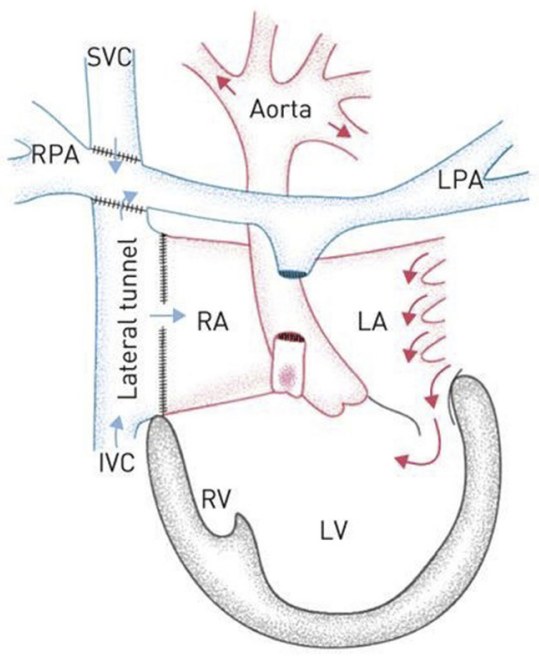

B

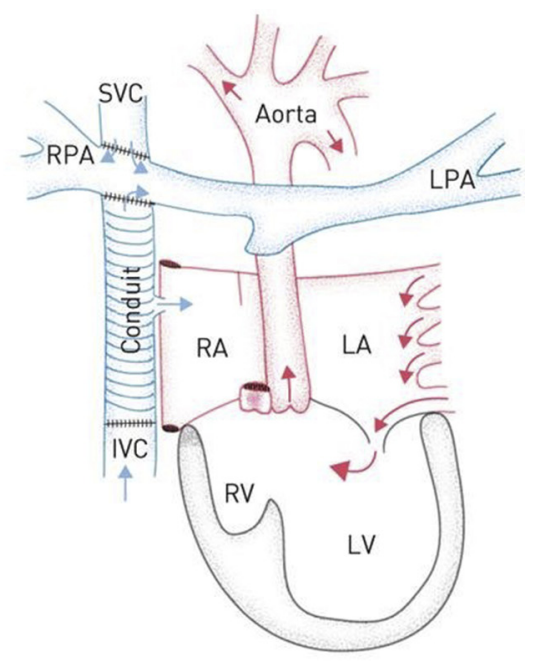

C TCPC (extracardiac conduit)

FIGURE 1. The Fontan circulation. A, Atriopulmonary anastomosis. B, Lateral tunnel. C, Extracardiac conduit. RPA, Right pulmonary artery; $L P A$, left pulmonary artery; $S V C$, superior vena cava; $R A$, right atrium; $L A$, left atrium; $I V C$, inferior vena cava; $R V$, right ventricle; $L V$, left ventricle, $T C P C$, total cavopulmonary connection. (Reproduced with permission of the @ ERS 2018: European Respiratory Review 25(142):438-450; https://doi.org/10.1183/ 16000617.0091-2016. Published 30 November 2016.) 
transpulmonary gradient; and postoperative pleural effusion, chylothorax, and ascites are predictors of prolonged ICU LOS. These factors either contribute to or result from the impediment to systemic venous flow, which is critical to adequate functioning of the Fontan circulation. Their second key finding is that ICU LOS was again associated with worse late outcomes.

These findings provide a set of potentially modifiable risk factors that span the life course of the Fontan palliation. Together, they should be viewed as another challenge to the multidisciplinary team treating these complex patients. Anomalous systemic venous drainage and aortopulmonary collaterals result in undesirable flow dynamics before the Fontan procedure, including inadequate pulmonary artery growth, venous hypertension, and elevated transpulmonary gradient, which all negatively influence Fontan circulation. ${ }^{9,10}$ Strong consideration should be paid to catheter occlusion of aortopulmonary collaterals, repair of pulmonary artery distortion, and pulmonary vasodilator therapy to reduce transpulmonary gradients before or at the time of Fontan completion. Development of novel methods to improve venous congestion and revisiting criteria for Fontan fenestration may also be warranted. Further, attention to venous flow patterns and hemodynamic parameters should extend beyond the perioperative period, when additional opportunities for early intervention may prevent late effects. In the study by Ono and colleagues, ${ }^{8}$ prolonged pleural drainage was the main contributor to increased ICU LOS. Respiratory insufficiency, inefficient Fontan circulation from elevated venous pressure, decreased oncotic pressure, and increased infection risk from protein and immunoglobulin loss may all mediate this negative association. ${ }^{11,12}$ Aggressive and systematic medical, interventional, and surgical management strategies to decrease pleural drainage should be implemented and have previously been shown to improve outcomes. ${ }^{13,14}$

It is evident that there is a subset of patients who experience extended ICU LOS after undergoing the Fontan operation. The need to develop new or adaptable interventions in this population is vital and will require careful investigation. However, the impetus to reduce ICU LOS using a multimodal approach throughout the perioperative period has never been clearer.

\section{References}

1. Fontan F, Baudet E. Surgical repair of tricuspid atresia. Thorax. 1971;26:240-8.

2. Atz AM, Zak V, Mahony L, Uzark K, D'Agincourt N, Goldberg DJ, et al. Longitudinal outcomes of patients with single ventricle after the Fontan procedure. J Am Coll Cardiol. 2017;69:2735-44.

3. d'Udekem Y, Iyengar AJ, Galati JC, Forsdick V, Weintraub RG, Wheaton GR, et al. Redefining expectations of long-term survival after the Fontan procedure: twenty-five years of follow-up from the entire population of Australia and New Zealand. Circulation. 2014;130(11 Suppl 1):S32-8.

4. Iyengar AJ, Winlaw DS, Galati JC, Wheaton GR, Gentles TL, Grigg LE, et al. The extracardiac conduit Fontan procedure in Australia and New Zealand: hypoplastic left heart syndrome predicts worse early and late outcomes. Eur J Cardiothorac Surg. 2014;46:465-73.

5. Kamata M, Stiver C, Naguib A, Tumin D, Tobias JD. A retrospective analysis of the influence of ventricular morphology on the perioperative outcomes after Fontan surgery. J Cardiothorac Vasc Anesth. 2017;31:128-33.

6. Ohuchi H, Miyazaki A, Negishi J, Hayama Y, Nakai M, Nishimura K, et al. Hemodynamic determinants of mortality after Fontan operation. Am Heart J. 2017;189:9-18.

7. Downing TE, Allen KY, Glatz AC, Rogers LS, Ravishankar C, Rychik J, et al. Long-term survival after the Fontan operation: twenty years of experience at a single center. J Thorac Cardiovasc Surg. 2017; 154:243-53.e2.

8. Ono M, Burri M, Balling G, Beran E, Cleuziou J, Pabst von Ohain J, et al. Predicted clinical factors associated with the intensive care unit length of stay following total cavopulmonary connection. J Thorac Cardiovasc Surg. 2019; 157:2005-13.e3

9. Grosse-Wortmann L, Drolet C, Dragulescu A, Kotani Y, Chaturvedi R, Lee KJ, et al. Aortopulmonary collateral flow volume affects early postoperative outcome after Fontan completion: a multimodality study. J Thorac Cardiovasc Surg. 2012; 144:1329-36.

10. Odenwald T, Quail MA, Giardini A, Khambadkone S, Hughes M, Tann O, et al Systemic to pulmonary collateral blood flow influences early outcomes following the total cavopulmonary connection. Heart. 2012;98:934-40.

11. Gupta A, Daggett C, Behera S, Ferraro M, Wells W, Starnes V. Risk factors for persistent pleural effusions after the extracardiac Fontan procedure. J Thorac Cardiovasc Surg. 2004;127:1664-9.

12. Mascio CE, Austin EH III. Pleural effusions following the Fontan procedure. Curr Opin Pulm Med. 2010;16:362-6.

13. Pike NA, Okuhara CA, Toyama J, Gross BP, Wells WJ, Starnes VA. Reduced pleural drainage, length of stay, and readmissions using a modified Fontan management protocol. J Thorac Cardiovasc Surg. 2015;150:481-7.

14. Sunstrom RE, Muralidaran A, Gerrah R, Reed RD, Good MK, Armsby LR, et al. A defined management strategy improves early outcomes after the Fontan procedure: the PORTLAND protocol. Ann Thorac Surg. 2015;99: 148-55. 